\title{
Do health behaviours explain socio-economic differences in all-cause mortality, and in fatal and non-fatal cardiovascular events? Evidence from the PRIME Study
}

\author{
J. V. Woodside ${ }^{1}$, J. W. G. Yarnell ${ }^{1}$, C. C. Patterson ${ }^{1}$, D. R. Arveiler ${ }^{2}$, P. Amouyel ${ }^{3}$, J. Ferrieres ${ }^{4}$, \\ A. Bingham ${ }^{5}$ and P. Ducimetiere \\ ${ }^{1}$ School of Medicine, Dentistry and Biomedical Sciences, Queen's University Belfast, Belfast BT12 6BJ, UK, \\ ${ }^{2}$ MONICA-Strasbourg, Strasbourg, France, ${ }^{3}$ MONICA-Lille, Lille, France, ${ }^{4}$ MONICA-Toulouse, Toulouse, \\ France and ${ }^{5}$ INSERM U780, Villejuif, France
}

The present study aimed to examine the contribution of health behaviours to the socio-economic gradient in all-cause mortality and in fatal or non-fatal cardiovascular events.

A total of 10593 men aged 50-59 years were examined in 1991-4 in centres in Northern Ireland and France. Men were screened for evidence of CHD and followed annually for 10 years by questionnaire for incident cases of CHD and stroke. Deaths and cardiovascular events (coronary deaths, myocardial infarction and stroke) were documented by clinical records and were reviewed by a medical committee. Eight indicators of socio-economic status were used including educational level and a summary index of material conditions. Health behaviours included lifetime smoking habit (pack years), alcohol consumption, physical activity and fruit and vegetable consumption.

At 10 years of follow-up there were 544 deaths from any cause and 440 fatal and non-fatal cardiovascular events in men without evidence of CVD at baseline. Socio-economic gradients were evident for all health behaviours. After adjustment for country and age socio-economic gradients were further adjusted for health behaviours. For fatal and non-fatal cardiovascular events by 10 years of followup health behaviours 'explained' $46 \%$ and $36 \%$ of the socio-economic gradient in education level and material conditions respectively (see Table). Additional adjustment for established risk factors increased the proportion of the socio-economic gradient accounted for.

Table. Risk (hazard ratio) of death or cardiovascular event at 10 years

\begin{tabular}{|c|c|c|c|c|c|c|}
\hline \multirow[b]{2}{*}{ Socio-economic factors } & \multicolumn{3}{|c|}{ All deaths ( $n$ 544) } & \multicolumn{3}{|c|}{ Cardiovascular events $(n$ 440) } \\
\hline & $\begin{array}{l}\text { Adjusted for } \\
\text { country and age }\end{array}$ & $\begin{array}{l}\text { Adjusted also for } \\
\text { health behaviours }\end{array}$ & $\%$ explained & $\begin{array}{l}\text { Adjusted for } \\
\text { country and age }\end{array}$ & $\begin{array}{l}\text { Adjusted also for } \\
\text { health behaviours }\end{array}$ & $\%$ explained \\
\hline Educational level** & 0.61 & 0.74 & 33 & 0.76 & 0.87 & 46 \\
\hline Material conditions $\dagger$ & 0.51 & 0.61 & 21 & 0.73 & 0.83 & 36 \\
\hline
\end{tabular}

* Higher $v$. primary education. †High $v$. low material condition.

In the present study health behaviours in men, assessed at 50-59 years, appeared to contribute only moderately to the socio-economic gradients in cardiovascular incidence and in all-cause mortality, but established risk factors make a further substantial contribution to this gradient. 